\title{
No effect of a high-fat diet on promotion of sex hormone-induced prostate and mammary carcinogenesis in the Noble rat model
}

\author{
G. Leung ${ }^{1,2}$, I. F. F. Benzie ${ }^{3}$, A. Cheung ${ }^{1}$, S. W. Tsao ${ }^{1}$ and Y. C. Wong ${ }^{1 *}$ \\ ${ }^{1}$ Department of Anatomy, Faculty of Medicine, ${ }^{2}$ Central Laboratory of the Institute of Molecular Technology for Drug \\ Discovery and Synthesis, University of Hong Kong, Hong Kong \\ ${ }^{3}$ Department of Nursing and Health Sciences, The Hong Kong Polytechnic University, Hung Hom, Hong Kong
}

(Received 4 December 2001 - Revised 29 April 2002 - Accepted 6 June 2002)

\begin{abstract}
Results of international correlation and migrant studies suggest that dietary fat promotes carcinogenesis in hormone-sensitive sites, but this is disputed. In the present study, we used a Noble rat model of sex hormone-induced cancers to examine the effect of a high-fat diet on the incidence and latency of prostate and mammary cancer in male $(n 139)$ and female $(n$ 72) animals respectively. We also measured $\alpha$-tocopherol levels in female breast tissue to determine whether a high intake of polyunsaturated fatty acids depletes antioxidant defence in target tissues, providing a possible potentiating mechanism for carcinogenesis. Results showed a very high incidence of hormone-induced adenocarcinomas of prostate and mammary gland, irrespective of diet. There was no difference in the pattern of carcinogenesis in different prostatic locations, weight of the prostate, or weight gain between male rats on the high-fat diet compared with the control (standard, low-fat) diet. In female rats, the incidence of mammary cancer and the body-weight gain were the same in both dietary groups, and breast $\alpha$-tocopherol was also unaffected by dietary fat intake. Our present results are supportive of recent cohort studies that reported no significant association between intake of fat and the development of human prostate and breast cancer, and do not support a role for dietary fat in promoting sex hormone-induced prostate and mammary carcinogenesis.
\end{abstract}

Noble rats: Prostate cancer: Breast cancer: Carcinogenesis: Dietary fat: Vitamin E

The global incidence of cancer is increasing both absolutely and in relation to other diseases, and the incidence is projected to rise from $10 \cdot 3$ million cases in 1996 to 14.7 million in 2020 (World Cancer Research Fund/ American Institute for Cancer Research, 1997). In western countries, prostate cancer and breast cancer are a major public health concern. These are the two most common cancers and are second only to lung cancer as a cause of cancer mortality among American men and women respectively (Jemal et al. 2002).

There are significant differences in breast- and prostatecancer incidence and mortality rates in different parts of the world (Rose et al. 1986; Landis et al. 1999). Compared with the USA, the incidence and age-adjusted mortality rates of both breast and prostate cancer are up to 10-fold lower in Asian countries (Hursting et al. 1990; Whittemore et al. 1995; Zock, 2001). In Asian groups who have migrated to the USA, however, prostate- and breastcancer rates tend to increase rapidly and immigrants acquire the cancer risk profiles of the host country
(Parkin et al. 1993; Angwafo, 1998). The changing pattern of risk that occurs after migration from, usually, a country of low risk to one of high risk supports the concept that most human cancers arise not just from simple inherited predispositions, but also by interaction with the environment. Further, as inhabitants of Asian countries adapt western-style diets, the incidence of prostate and breast cancers increases (Haenszel \& Kurihara, 1968). Results from population and migrant studies have led to the general belief that diet, particularly with reference to intake of fat, is an important determinant of common cancers such as breast and prostate cancer. The National Academy of Sciences report on diet, nutrition and cancer in 1982 and the subsequent report on diet and health in 1989 (Committee on Diet, Nutrition, and Cancer, National Research Council, 1982; Committee on Diet and Health, National Research Council, 1989) both concluded there was a causal relationship between dietary fat and cancer. However, this has been disputed recently in the World Cancer Research Fund reports (World Cancer Research

Abbreviations: LF, low fat; HF, high fat.

*Corresponding author: Professor Y. C. Wong, fax +852 2817 0857, email ycwong@hkucc.hku.hk 
Fund/American Institute for Cancer research, 1997) and studies of experimental carcinogenesis using rat models have produced controversial views on the link between prostate cancer and consumption of a high-fat (HF) diet (Pollard \& Luckert, 1986; Carroll \& Noble, 1987; Pour et al. 1991; Takai, 1991; Kondo et al. 1994). Most experiments in male rats have resulted in only a small number of cases of prostate cancer in animals fed a $\mathrm{HF}$ diet. Furthermore, dietary studies on female rats and mice have generally used chemical carcinogens, usually 1,2-dimethylbenz $(\alpha)$ anthracene or $N$-methylnitrosourea (Freedman et al. 1990; Clarke, 1997) to induce mammary tumourigenesis. A useful alternative approach to the study of carcinogenic influences on sex-hormone-related cancers is the Noble rat model, first used by Noble and his colleagues (Noble, 1976, 1977). Our laboratory has established a modified approach, using a higher dosage of testosterone and $17 \beta$-oestradiol, to give a high incidence of prostate and mammary cancer in a shorter period of time, and have used this model successfully in prostate- (Wang \& Wong, 1998; Wong et al. 1998; Tam et al. 2000; Wong \& Wang, 2000; Wong et al. 2000; Xie et al. 2000b,c; Ouyang et al. 2001) and breast- (Xie et al. 1999a,b,c,d, 2000a; Leung et al. 2002) cancer studies. We consider sex-hormone induction in Noble rats an appropriate model, as carcinoma of both prostate and breast are sexhormone related, and this model can induce a high incidence of both types of tumours. Moreover, the growth patterns and histopathology of the tumours induced in the Noble rat model have a high resemblance to the features of their counterpart in human subjects (Wang \& Wong, 1998; Xie et al. 1999b)

In the present study, we evaluated the effect of a HF diet on prostate and mammary tumour development burden, using the Noble rat model of sex-hormone-induced cancer. Maize oil, a cooking oil commonly consumed by western populations, was used as the source of dietary fat for the animals. This has a high content of the $n-6$ polyunsaturated fatty acid linoleic acid (Escrich et al. 1994). It has been suggested that eicosanoids formed from linoleic acid by lipoxygenase action have a key role in breast-cancer growth, invasion and metastasis (Rose et al. 1991) and on prostate-cancer cell growth in vitro (Rose \& Connolly, 1991). Furthermore, it has been proposed (Bartsch et al. 1999) that peroxidation of conjugated double bonds in polyunsaturated fatty acids (such as linoleic acid), leads to persistent oxidative stress and generation of reactive lipid peroxidation products that can induce DNA damage and contribute towards carcinogenesis (Vaca et al. 1988; Chung et al. 1996). Many antioxidants, such as the lipophilic $\alpha$-tocopherol have been considered protective against cancer (Statland, 1992). In the present study, therefore, we also investigated the concentration of $\alpha$-tocopherol (vitamin E) in the breast tissue of female Noble rats treated with sex hormones for 4 months. Our working hypothesis with regard to this part of the present study was that high intake of polyunsaturated fatty acids would deplete antioxidant defence in the target tissue and that this, in turn, would have a promoting effect on breast cancer, potentiating the effect of eicosanoids and oxidative stress. The serum concentration of testosterone and oestradiol were also measured at regular intervals to see if there was any dietary influence on the metabolism of these hormones, as it has also been suggested that a HF diet may increase the concentration of free fatty acids in serum and, in turn, displace oestrogen from serum albumin, making it free for uptake by oestrogen receptors (Bartsch et al. 1999).

\section{Materials and methods}

Diets

Rodent Laboratory Diet (PMI Feeds Inc., St Louis, MO, USA) was used as the standard low-fat (LF) diet and the HF diet was prepared by adding Mazola ${ }^{\circledR}$ maize oil (CPC International Inc., Englewood Cliffs, NJ, USA) to the standard diet to give an additional fat content of $200 \mathrm{~g} / \mathrm{kg}$. Thus, the total fat content of the LF diet was $45 \mathrm{~g} / \mathrm{kg}$ as stated by the supplier, and that of the HF diet was $245 \mathrm{~g} / \mathrm{kg}$. The $\mathrm{HF}$ diet was prepared once per week and stored at $4^{\circ} \mathrm{C}$ until used. According to the producer (CPC International Inc.) the fat content of Mazola ${ }^{\circledR}$ maize oil is $(\mathrm{g} / 100 \mathrm{~g}$ total fat): saturated fat $14 \cdot 3$, polyunsaturated fat $57 \cdot 1$, monounsaturated fat $24 \cdot 6$.

\section{Hormones}

Capsules of powdered testosterone as testosterone propionate (Sigma, St Louis, MO, USA) and 17 $\beta$-oestradiol (Fluka, Buchs, Switzerland) were prepared by handpacking, separately, medical grade silastic tubing (no. 602-305 tubing, internal diameter $1.54 \mathrm{~mm}$, external diameter $3.18 \mathrm{~mm}$; Dow-Corning Corporation, Midland, MI, USA) and sealing this with medical silicone adhesive (RTV-108; General Electric, Waterford, NY, USA). Each $2 \mathrm{~cm}$ capsule contained $30 \mathrm{mg}$ testosterone and each $1.0 \mathrm{~cm}$ capsule $22 \mathrm{mg} 17 \beta$-oestradiol. Empty capsules were prepared for the control rats.

\section{Animal models}

Male and female Noble rats, weaned and aged 1 month, were housed separately and randomly divided into two dietary (LF and HF) groups. One group was fed with HF diet (the experimental group) and the other with LF diet for the next 2 months. At 3 months of age, the (now) sexually mature Noble rats were implanted, under sterile conditions, with capsules (either containing hormone, or empty capsules for hormone control rats) in the subcutaneous space between the scapulae. Male rats were implanted with six testosterone capsules and one $17 \beta$-oestradiol capsule and female rats were implanted with two testosterone capsules and one 17 $\beta$-oestradiol capsule. Age- and sex-matched rats in each of the two dietary groups were implanted with empty capsules. All capsules were replaced at 12-week intervals and all rats were allowed to have food and water ad libitum and housed under controlled conditions $(12 \mathrm{~h}$ light-dark cycle, $22 \pm 2^{\circ} \mathrm{C}$ ). The body weight of each rat was recorded once per week. Male rats from each group were killed by cervical dislocation at 3, 4, 6, 8, 10 
months after implantation and examined for the appearance and progress of prostate tumours. Female rats in each group were palpated regularly for mammary tumours, starting from 2 months after the capsules were implanted. Rats were killed when the palpated tumour masses exceeded $2 \mathrm{~cm}$ in diameter or when the animals became moribund. All remaining female rats were killed 12 months after hormone implantation. At the end of the experimental period, 211 rats had been investigated: 108 (males $n$ 72, females $n$ 36) received the HF diet; 103 (males $n$ 67, females $n$ 36) received the LF diet. With regard to hormone treatment, 139 of these rats (males $n$ 91, females $n$ 48) received hormones, and seventy-two rats (males $n$ 48, females $n$ 24) did not. At the end of the experimental period, the animals were killed by cervical dislocation.

To measure the concentration of $\alpha$-tocopherol in the breast tissue, another four groups of female rats (following the protocol as described earlier) were kept for 4 months before killing, and the breast tissue excised and extracted. There were forty rats in this group, twenty on each diet; thirty-two rats received hormone treatment and eight did not.

Based on results from male rats, a follow-up study was performed in which fifty additional male rats were implanted with half the dose of testosterone (i.e. $90 \mathrm{mg}$ testosterone) and fed HF ( $n$ 25) or LF (n 25) diets. Apart from the smaller dose of testosterone, all other aspects of this follow-up study, including the dose of $17 \beta$-oestradiol, were the same as in the main study.

\section{Autopsy and pathological examination}

The prostate glands were excised, the dorsal, lateral and ventral lobes were dissected out, and the wet weight of the whole prostate and individual lobes were recorded before they were fixed in buffered formalin $(100 \mathrm{ml} / \mathrm{l})$, processed and embedded into paraffin wax. Paraffin sections of $4 \mu \mathrm{m}$ were prepared, stained with haematoxylin resin and examined by bright-field microscopy. Mammary glands and any tumours were removed and fixed in neutral buffered formalin and similarly processed and stained with haematoxylin and eosin. Histopathology of prostate glands was based on the criteria and classification outlined previously (Wang \& Wong, 1998; Wong et al. 1998) and that of the mammary glands were based on the criteria and classification of breast pathology outlined by Rosen (1997).

\section{Measurement of testosterone and oestradiol in serum}

Blood samples were collected once per month from the tail of a subsample of animals in each subgroup $(n 6)$ to evaluate the circulatory sex hormone levels. Serum was collected and stored at $-20^{\circ} \mathrm{C}$. At the time of killing, heart blood of the animals was also collected. The serum testosterone concentration was determined by an ELISA method (EIAgen Testosterone kit; BioChem ImmunoSystems, Rome, Italy). The serum oestradiol concentration was measured by an ELISA (VIDAS Oestradiol
II Kit and mini VIDAS instrument; BioMerieux Vitek, Marcy L'Etoile, France).

\section{$\alpha$-Tocopherol analysis on breast tissues}

Preparation of the tissue for analysis was performed according to method of Sheehy et al. (1994). At killing, the thoracic mammary glands of the female rats were dissected and snap frozen with liquid $\mathrm{N}_{2}$ and stored at $-80^{\circ} \mathrm{C}$ before the extraction process. All visible fat and any loose connective tissue were trimmed away. A homogenate of breast tissue $(200 \mathrm{~g} / \mathrm{l} \mathrm{KCl}(11.5 \mathrm{~g} / \mathrm{l})$ was prepared. A sample of homogenate $(1 \mathrm{ml})$ was transferred into a $10 \mathrm{ml}$ screw-capped Pyrex tube fitted with a Teflon-lined cap. A duplicate sample was spiked with

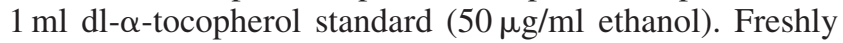
prepared pyrogallol $(2 \mathrm{ml} ; 10 \mathrm{ml} / \mathrm{l}$ ethanol) was added to each tube. Homogenates were saponified in a water-bath at $70^{\circ} \mathrm{C}$ for $30 \mathrm{~min}$ and then cooled on ice. After addition of $1 \mathrm{ml}$ distilled water and $4 \mathrm{ml}$ hexane (with $0.05 \mathrm{ml}$ butylated hydroxytoluene/l), the tubes were vortexed thoroughly and centrifuged at $2500 \mathrm{rpm}$ for $10 \mathrm{~min}$. The upper hexane layer was removed and the homogenate was re-extracted with $2 \mathrm{ml}$ hexane (with $0.05 \mathrm{ml}$ butylated hydroxytoluene/l) prior to analysis. DL- $\alpha$-Tocopherol $(980-1020 \mathrm{~g} / \mathrm{kg})$ and toluene were purchased from Merck (Darmstadt, Germany), absolute ethanol and hexane were from Riedel-de Haen (Seelze, Germany), butylated hydroxytoluene was from Sigma and methanol (HiperSolv for HPLC) was from BDH Laboratory Supplies (Poole, Dorset, UK).

\section{HPLC analysis}

The chromatography system comprised an Alliance 2690 Separations Module with temperature-controlled column chamber and autosampler (Waters, Milford, MA, USA), Waters 996 Photodiode Array Detector and Waters Millennium 32 PDA software (version 3.05.01), a reverse-phase $\mathrm{C}_{18}$ analytical column $(5 \mu \mathrm{m}, 250 \times 5 \mathrm{~mm}$ internal diameter; Isco Inc., Lincoln, NE, USA) and a cartridge guard column (Spherisorb $\mathrm{C}_{18}, 5 \mu \mathrm{m}$, cartridge $10 \times 5 \mathrm{~mm}$ internal diameter; Isco Inc.). The mobile phase was methanol-toluene (80: 20, v/v), which was filtered and degassed through a Millipore membrane (type GV, pore size $0.22 \mu \mathrm{m}$; Millipore Corp., Bedford, MA, USA) before use. The detection was set at $292 \mathrm{~nm}$ and the flow rate was $1.0 \mathrm{ml} / \mathrm{min}$. The column worked at room temperature, but the cooling chamber of the autosampler was set at $4^{\circ} \mathrm{C}$. Freshly prepared calibrators $(10,20,30$ and $40 \mu \mathrm{mol}$ $\alpha$-tocopherol/l ethanol) were used to construct the calibration curve. The calibrators were temporarily stored in an icebath and protected from light during preparation. Once prepared, $100 \mu \mathrm{l}$ of each calibrator were transferred into a small glass vial fitted with a micro-glass insert and the vial was placed inside the autosampler at $4^{\circ} \mathrm{C}$. Each calibrator $(20 \mu \mathrm{l})$ was injected into the HPLC system.

\section{Measurement of sample extracts and calculations}

Each of the sample extracts in $200 \mu$ l ethanol as described earlier was diluted ten times in ethanol and $20 \mu$ l diluted 
extract was injected into the column. The peak area of $\alpha$-tocopherol was used as the variable for determination. From the slope of the standard curve, the concentration $(\mu \mathrm{mol} / \mathrm{l})$ of $\alpha$-tocopherol in each diluted sample extract was calculated simply by the peak area of sample over the slope of the calibration curve, and the result was dilution-corrected and expressed as $\mu \mathrm{mol} / \mathrm{l}$ for direct comparison of tissue extracts.

\section{Statistical analysis}

Comparison of body weight and wet weight of target tissue between groups was by one-way ANOVA. Differences in incidence of carcinoma in different sites in the different groups and subgroups were tested by $\chi^{2}$ and Fisher's exact test. Significance at $P<0.05$ was sought.

\section{Results}

\section{Prostatic carcinogenesis in male Noble rats}

Male rats were killed at different time points (3, 4, 6, 8, 10 months) to determine the incidence, mass and different stages of prostatic carcinogenesis. At autopsy, the prostate gland of hormone-treated animals showed gross enlargement and the wet weights of the prostate gland of these animals were significantly $(P<0.05)$ greater than those of the animals receiving no hormone. However, there was no significant difference detected in the weight of the prostate glands between the experimental and control dietary groups (Fig. 1).

Histological examination of the prostate glands of the hormone-treated male rats showed pre-malignant and malignant changes, whereas no such changes were seen

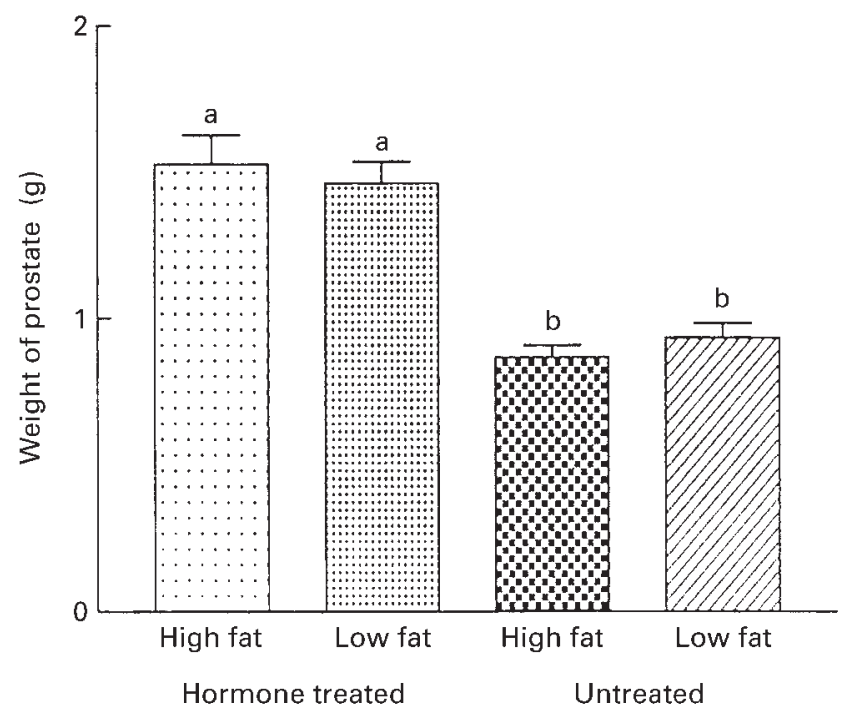

Fig. 1. Effect of a high- or low-fat diet on the weight of the prostate gland of male Noble rats at 6 months post implantation of capsules containing $180 \mathrm{mg}$ testosterone propionate and $22 \mathrm{mg}$ $17 \beta$-oestradiol or empty control capsules (capsules were replaced at 12-week intervals). For details of diets and procedures, see p. 400. Values are means with their standard errors represented by vertical bars. ${ }^{a, b}$ Mean values with unlike superscript letters were significantly different (one-way ANOVA, $P<0.05$ ).

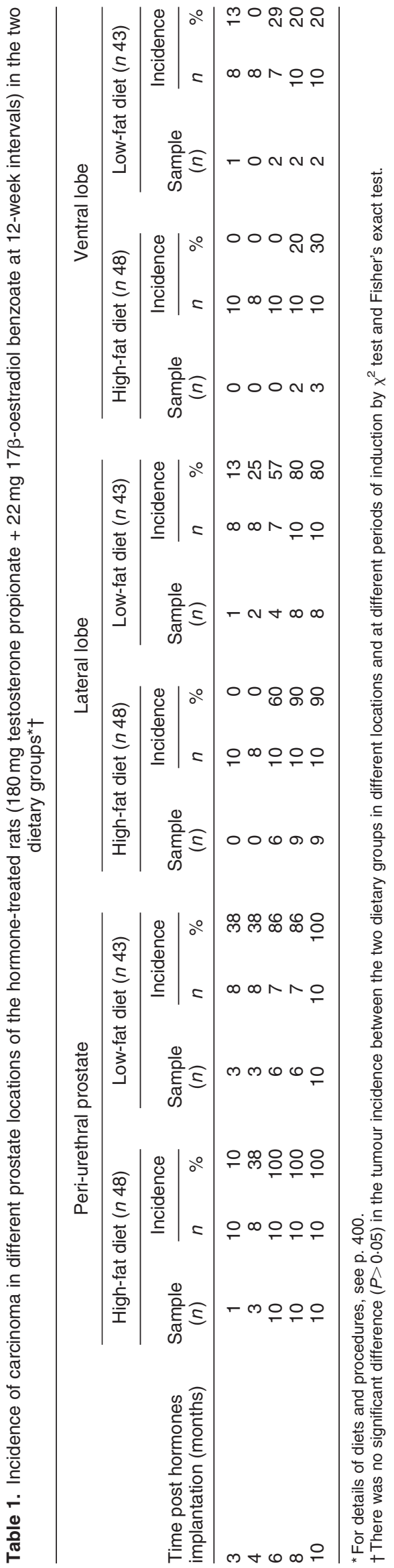


in the rats receiving no hormone treatment, regardless of diet. In the male rats treated with the high dosage of hormone (180 mg testosterone and $22 \mathrm{mg} 17 \beta$-oestradiol), after 6 months of hormone treatment there was an incidence of adenocarcinoma of nearly $100 \%$ in the periurethral prostate in the hormone-treated rats, irrespective of the type of diet (Table 1). Tumours were mostly well differentiated and arose from the peri-urethral ducts of the dorsal and lateral prostate (Fig. 2(a)). It was also apparent that the tumours tended to spread into the ducts of the lateral lobe and from there into the stroma of the lateral lobe (Fig. 2(b and c)). In the lateral lobe, glandular dysplastic lesions were common with increasing incidence of carcinoma noted with duration of treatment (Fig. 2(c)). In the ventral lobe, glandular hyperplastic and dysplastic lesions were more frequently observed. Carcinoma of the ventral lobe was present in $20-30 \%$ of animals treated for 10 months, but these tumours were mostly in focal areas at the periphery of the lobe (Fig. 2(d)). There were no tumours arising from the dorsal lobe. All prostatic tumours identified were organ-confined without metastasis to other organs within the experimental period. In the follow-up study using the smaller dose of testosterone (90 mg testosterone and $22 \mathrm{mg} 17 \beta$-oestradiol), a similar pattern was seen except that the tumours developed more slowly and there was a lower incidence of adenocarcinoma of the peri-urethral prostate (Table 2). No significant difference $(P>0.05)$ was found in the incidence of prostatic carcinoma, dysplasia and hyperplasia in the different locations between the two dietary groups at different periods of induction, irrespective of the dose of testosterone. None of the animals not receiving hormone treatment showed any prostate tumourigenesis.

The body weight of the four subgroups of male rats showed no significant difference before hormone treatment (Fig. 3). The body weight of the animals treated with hormones in both diet groups showed an initial decline after 1 month, after which body weight remained constant. There was no significant difference in the body weight of the hormone-treated animals in the HF and LF groups at different time points. The animals given no hormone gained weight steadily, and these animals were significantly heavier than the hormone-treated animals at all time points from 1 month after implantation. In addition, there was significantly $(P<0.05)$ greater weight gain shown by the HF dietary group receiving no hormone treatment at all time points after 2 months. In the hormone-treated rats, circulatory testosterone levels increased 5-30-fold and serum oestradiol levels increased 3-9-fold compared with age- and diet-matched controls. There was no significant difference in the serum hormone levels between the HF and LF groups (results not shown).

\section{Mammary carcinogenesis of female Noble rats}

No tumours developed in the rats not treated with hormones, irrespective of diet. In the rats receiving hormone treatment, palpable mammary tumour masses first appeared at 5 months post implantation in both experimental dietary groups. Cumulative incidences of mammary carcinoma in the two groups were 79 and $63 \%$ in the HF- and LF-diet groups respectively (Fig. 4),
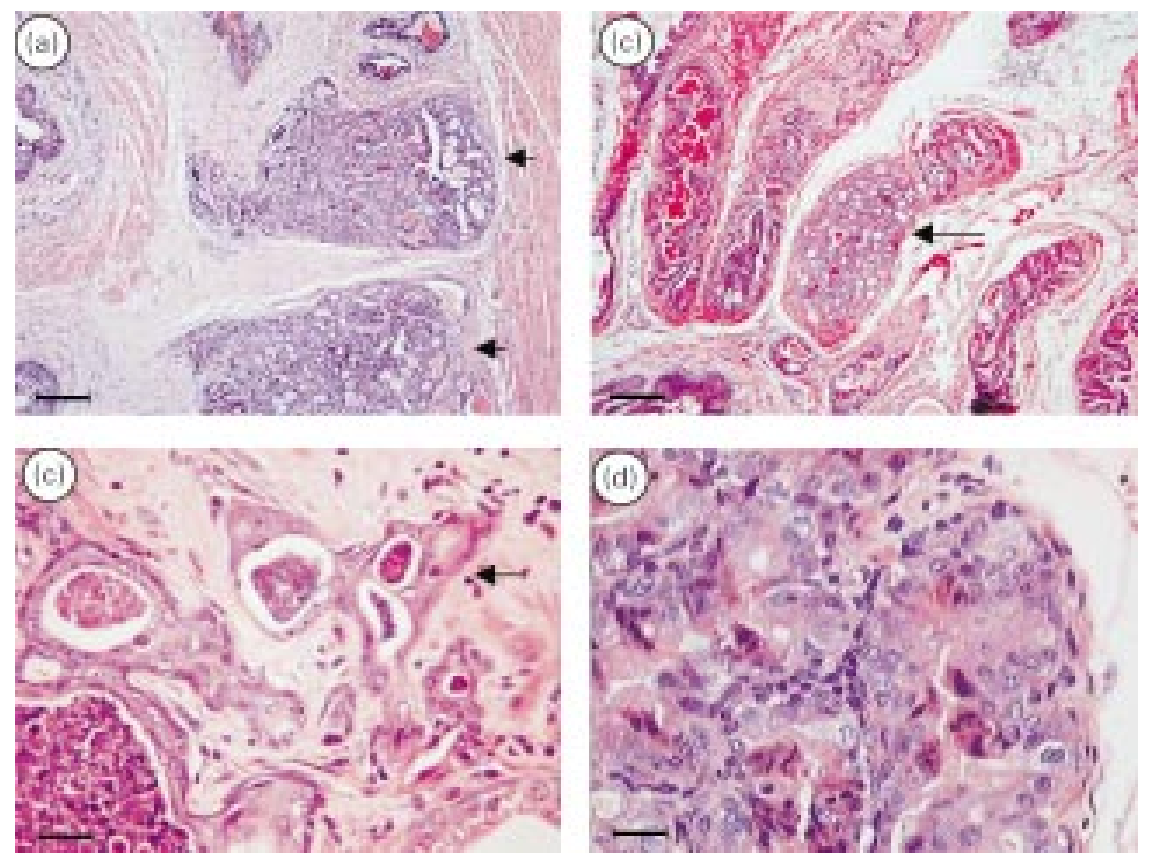

Fig. 2. Histopathology of prostate carcinogenesis in male Noble rats post implantation of $180 \mathrm{mg}$ testosterone propionate and $22 \mathrm{mg} \mathrm{17 \beta -oestradiol} \mathrm{(capsules} \mathrm{were} \mathrm{replaced} \mathrm{at}$ 12-week intervals). (a) well-differentiated adenocarcinoma arising from the peri-urethral ducts in the prostatic urethra $(\leftarrow)$; (b) spreading of cancer cells along the ducts towards the lateral lobe $(\leftarrow)$; (c) irregular acinar cells nests invading into the stroma of the lateral lobe $(\leftarrow)$; (d) foci of carcinoma at the periphery of the ventral lobe. $\mapsto, 20 \mu \mathrm{m}$. For details of diets and procedures, see p. 400. 


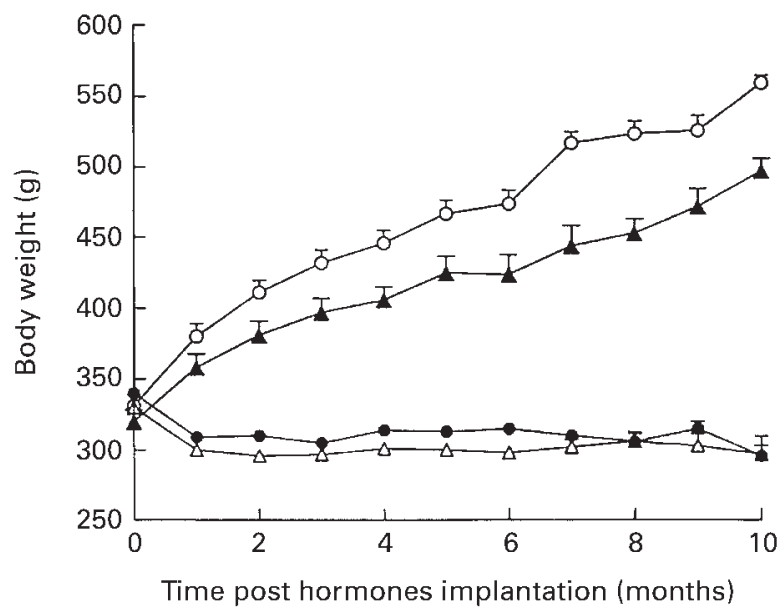

Fig. 3. Effects of a high-fat $(O, \bullet)$ or low-fat $(\triangle, \mathbf{\Delta})$ diets on the body weight of male Noble rats post implantation of capsules containing $180 \mathrm{mg}$ testosterone propionate and $22 \mathrm{mg} 17 \beta$-oestradiol $(\bullet, \Delta)$ or empty control capsules $(\mathrm{O}, \boldsymbol{\Delta})$ (capsules were replaced at 12-week intervals). For details of diets and procedures, see p. 400. Mean value for the body weight of hormone-treated rats fed on the high-fat diet was not significantly different from that of the low-fat group $(P>0.05)$. The mean body weight of the untreated control groups was significantly greater than that of the hormone-treated groups $(P<0.05)$.

with a slight but non-significant difference between the two experimental groups $(P>0 \cdot 05)$. Latency periods of tumourigenesis in both experimental groups were similar (Table 3). The mean number of tumour masses per hormone-treated female rat overall were 1.42 and 1.27 in the HF- and LF-diet groups respectively. The mammary tumours induced in both experimental dietary groups

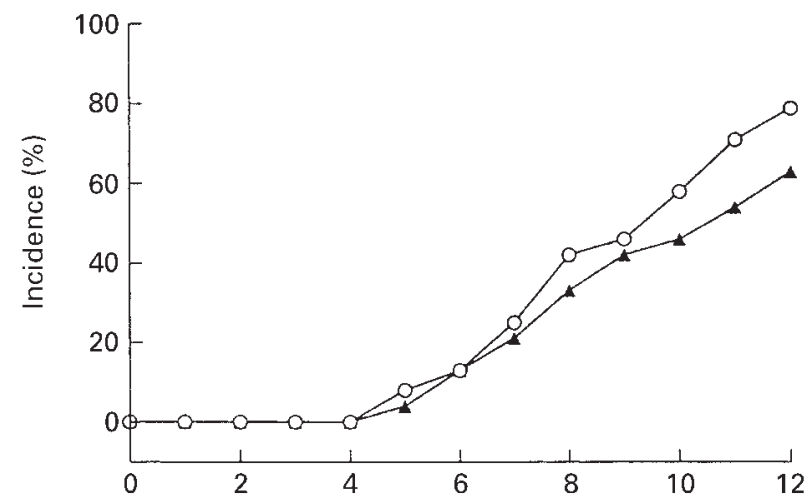

Time post hormones implantation (months)

Fig. 4. Cumulative incidence of development of mammary tumours in female Noble rats fed on low-fat $(\mathbf{\Lambda})$ or high-fat $(\bigcirc)$ diets post implantation of capsules containing $60 \mathrm{mg}$ testosterone propionate and $22 \mathrm{mg} 17 \beta$-oestradiol (capsules were replaced at 12-week intervals). For details of diets and procedures, see p. 400. Palpable mammary tumour masses first appeared at 5 months post implantation in both groups. Cumulative incidences of mammary carcinoma in the two groups were 79 and $63 \%$ for low-fat and highfat groups respectively. The mean values for tumour incidence and latency period in the high-fat group were not significantly different from those of the low-fat group. None of the animals in the untreated control groups developed tumours within 12 months (results from normal controls not shown in figure). 
Table 3. Induction of mammary tumours in Noble rats fed on high-fat or low-fat diets for 12 months $^{\star}$

\begin{tabular}{|c|c|c|c|c|c|c|}
\hline \multirow[b]{2}{*}{ Group } & \multirow[b]{2}{*}{ Diet and treatment } & \multirow[b]{2}{*}{$n$} & \multicolumn{2}{|c|}{$\begin{array}{l}\text { Rats with } \\
\text { tumour }\end{array}$} & \multicolumn{2}{|c|}{$\begin{array}{l}\text { Latency period } \\
\text { (months) }\end{array}$} \\
\hline & & & $n$ & $\%$ & Mean & SD \\
\hline 1 & High-fat hormone treated† & 24 & 19 & 79 & $8 \cdot 68$ & $2 \cdot 15$ \\
\hline 2 & Low-fat, hormone treated $†$ & 24 & 15 & 63 & $8 \cdot 60$ & $2 \cdot 15$ \\
\hline 3 & High-fat untreated $\ddagger$ & 12 & 0 & 0 & 0 & \\
\hline 4 & Low-fat untreated $\ddagger$ & 12 & 0 & 0 & 0 & \\
\hline
\end{tabular}

were largely ductal carcinomas of papillary, cribriform, comedo and solid types (Fig. 5), ranging from $8-35 \mathrm{~mm}$ in diameter at the time of autopsy. Extraductal invasions were common although no evidence of metastasis was found within the experimental period.

The body weight of the four subgroups of female rats showed no significant difference before hormone treatment (Fig. 6). Unlike the male rats, the female Noble rats had a gradual increase in body weight with hormone treatment. Starting from the fifth month, the weight of the hormone-treated animals on HF diet was slightly, but nonsignificantly, higher than the matching LF group. The body weights of the animals not receiving hormone were significantly greater than the corresponding hormone-treated animals at all time points after 3 months
$(P<0 \cdot 05)$. In the $\mathrm{HF}$ female rats, after hormone implantation serum testosterone levels increased 10-100-fold and oestradiol levels increased 4-5-fold compared with age- and diet-matched controls. No significant difference was seen in the hormone levels between the two experimental groups (results not shown).

\section{$\alpha$-Tocopherol analysis in breast tissue}

Mean recovery of $\alpha$-tocopherol in the spike samples was $90 \%$, which was considered good. The $\alpha$-tocopherol concentration in the breast tissue extracts is shown in Table 4. There was no effect of diet, as no significant difference was seen in the tissue $\alpha$-tocopherol level between the hormone-controlled subgroups. However, the
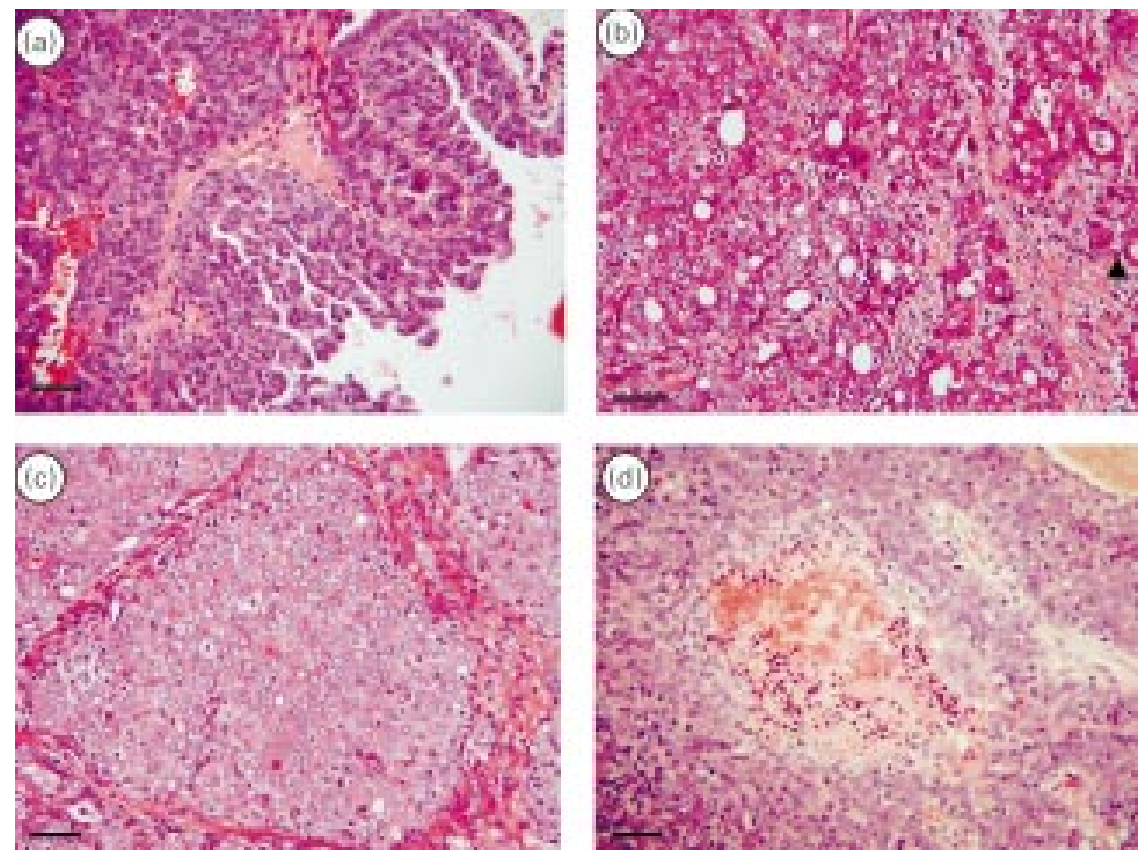

Fig. 5. Histopathology of mammary gland carcinogenesis in female Noble rats post implantation of $180 \mathrm{mg}$ testosterone propionate and $22 \mathrm{mg} 17 \beta$-oestradiol. (a) papillary pattern (papillary fronds are covered by hyperchromatic nuclei); (b) cribriform pattern (round or oval microlumina with smooth edges bordered by neoplastic cells; note the invasion of tumour cells into the stroma on the right $(\leftarrow)$ ); (c) solid pattern (the ductal lumen is totally obliterated by the proliferation of irregularly shaped nests of closely aggregated cells); (d) comedo pattern (central necrosis surrounded by bands of tumour cells). $\mapsto, 20 \mu \mathrm{m}$. For details of diets and procedures, see p. 400. 


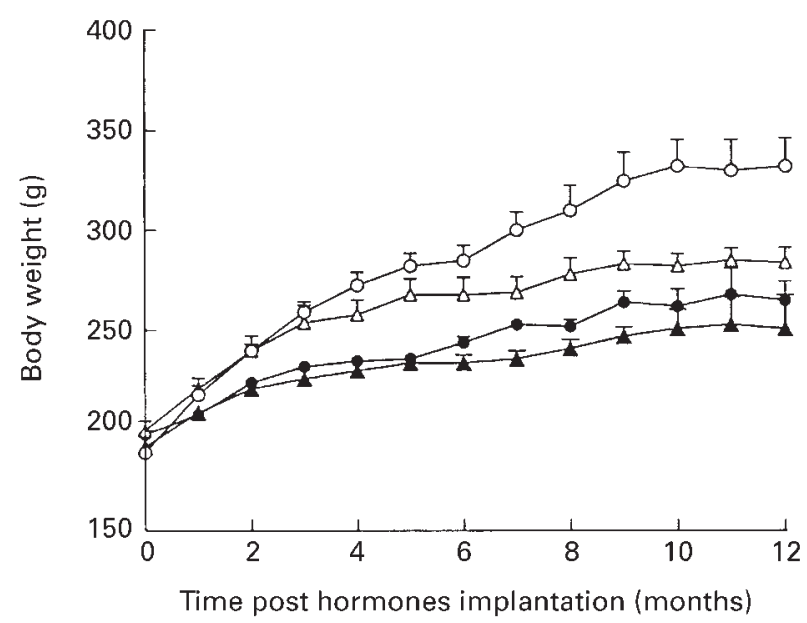

Fig. 6. Effects of a high-fat $(O, \bullet)$ or low-fat $(\triangle, \Delta)$ diets on the body weight of female Noble rats post implantation of capsules containing $60 \mathrm{mg}$ testosterone propionate and $22 \mathrm{mg} 17 \beta$-oestradiol $(\bullet, \triangle)$ or empty control capsules $(\bigcirc, \boldsymbol{\Lambda})$ (capsules were replaced at 12-week intervals). For details of diets and procedures, see p. 400. The mean body weight of hormone-treated rats fed on the high-fat diet was not significantly different from that of the low-fat group $(P>0.05)$. The mean body weight of both untreated control groups was significantly greater than that of the corresponding hormonetreated groups after 3 months $(P<0.01)$. The mean body weight of rats fed on the high-fat diet was significantly different from that of the low-fat group after 7 months $(P<0.05)$.

$\alpha$-tocopherol levels in the breast tissue of hormone-treated animals were significantly $(P<0.05)$ higher than those of the animals that did not receive hormone treatment.

\section{Discussion}

\section{Prostate carcinogenesis}

In the present study, a high incidence of prostate cancer was seen in male Noble rats (the set with higher dosage of hormone) within a relatively short period of time of hormone treatment, confirming the efficiency of the animal model and its usefulness for study of prostate cancer. Analysis of the different stages of carcinogenesis in the three different locations of the prostate (peri-urethral region, lateral and ventral lobes) at various induction periods showed similar incidences in both the LF- and HF-diet groups. This indicates that dietary fat has no influence per se on sex hormone-induced prostatic carcinogenesis. However, it is possible that the system was already maximally stimulated by the hormones, so that additional dietary intervention would not have any effect. To test this, we performed a follow-up study (as described on p. 401) in which male rats were implanted with half the dose of testosterone. Prostatic carcinoma developed more slowly with the lower hormonal stimulation, but results again showed no significant difference in the incidence of tumour development between the two diet groups. This is further indication that dietary fat itself does not promote carcinogenesis.

The growth of the male rats treated with sex hormones and fed with $\mathrm{HF}$ or standard (LF) diets was similar throughout the experimental period, indicating that there was no significant difference in energy intake and utilization
Table 4. Level of $\alpha$-tocopherol in the mammary tissue of Noble rats fed on high-fat or low-fat diets for 4 months $^{*} \dagger$

(Mean values and standard deviations)

\begin{tabular}{|c|c|c|c|c|}
\hline \multirow[b]{2}{*}{ Group } & \multirow[b]{2}{*}{ Diet and treatment } & \multirow[b]{2}{*}{$n$} & \multicolumn{2}{|c|}{$\begin{array}{c}\alpha \text {-Tocopherol } \\
\text { level }(\mu \mathrm{M}) \ddagger\end{array}$} \\
\hline & & & Mean & SD \\
\hline 1 & High-fat, hormone-treated§ & 16 & $400^{\mathrm{a}}$ & \\
\hline 2 & Low-fat, hormone-treated§ & 16 & $414^{a}$ & 159 \\
\hline 3 & High-fat, untreated\| & 4 & $297^{\mathrm{b}}$ & \\
\hline 4 & Low-fat, untreated\| & 4 & $287^{b}$ & 47 \\
\hline
\end{tabular}

a,b Mean values within a column with unlike superscript letters were significantly different $(P<0.05)$

${ }^{*}$ For details of diets and procedures, see p. 400.

$\dagger$ There was no significant difference in the levels of tissue $\alpha$-tocopherol between the two hormone-treated groups or that of the two untreated control groups.

$\ddagger$ All samples measured represent the same mass of tissue.

$\S$ Capsules containing testosterone propionate $(60 \mathrm{mg})+17 \beta$-oestradio benzoate $(22 \mathrm{mg})$ were implanted and replaced at 12-week intervals.

\| Empty capsules were implanted.

balance between these two groups. Being the target organs of testosterone influence, the size and weight of the prostate glands were much higher in hormone-treated animals. However, the lack of difference in prostate mass between the two dietary groups indicates that the influence of these additional hormones on the weight of the prostate gland and on the body as a whole was not affected by the fat content of diet. The HF and LF diets were not isoenergetic, as reported by others (Donato, 1987); however, the results suggest that the energy intake was similar in each dietary group. This supports the view that a high energy intake from an HF diet, rather than dietary fat itself, increases the risk of cancer (Ip, 1993).

There are a number of epidemiological and case studies of dietary influences on prostatic carcinogenesis (Blair \& Fraumeni, 1978; Kolonel et al. 1981; Graham et al. 1983; Rose et al. 1986; Hursting et al. 1990; Bravo et al. 1991; West et al. 1991; Pienta \& Esper, 1993). However, due to the lack of suitable animal models, there have been limited in vivo studies in this important area. Most recent laboratory research has been done on prostate cancer cell lines and transgenic mouse models, which are less comparable with the human situation (Rose \& Connolly, 1991; Wang et al. 1995; Pandalai et al. 1996; Aronson et al. 1999). Our present animal model closely mimics the different stages of prostatic carcinogenesis in human subjects, from pre-malignant to fully developed adenocarcinoma with different degrees of differentiation, although, in this current study, all the prostatic carcinomas induced were organ-confined and had not reached the stage equivalent to a clinically advanced, metastatic stage in human subjects. Nonetheless, the model is similar to the situation in human subjects, where there is a higher incidence of latent or micro-focal carcinoma of the prostate than advanced stage carcinoma. In human subjects, the incidence of latent carcinoma is relatively constant and unrelated to race, geography and difference in diet (Breslow et al. 1977; Sakr et al. 1993). It has been reported, however, that there is an association between high dietary fat intake and the risk of having advanced 
stage disease (Giovannucci et al. 1993). In our present model, tumour incidence was almost $100 \%$ after hormone treatment for 6 months; however, the HF diet did not effect the promotion of these cancers to an advanced stage within the experimental period.

\section{Mammary carcinogenesis}

In the current study, a very high incidence of mammary cancer was induced within 12 months of hormone treatment in both diet groups. The histopathological pattern of tumours induced and the mode of invasion were similar to that of the naturally occurring human breast cancer. The incidence and number of tumours developed per rat were slightly higher in the HF-diet group, but the difference was not statistically significant. The latency and pattern of tumour development were also similar in the two dietary groups. The results indicate that dietary fat has little influence on sex hormone-induced mammary carcinogenesis of the female Noble rat model. This is in general agreement with the results of Carroll \& Noble (1987), who used only oestrone, a more toxic form of oestrogen, for mammary carcinoma induction in Noble rats. In the past decades, it has been shown consistently that mice and rats fed HF diets develop mammary tumours more readily than control animals on LF diets when chemical carcinogens are used to induce carcinogenesis (Carroll \& Khor, 1970; Chan \& Dao, 1981; Tang et al. 1996). The difference between the ability of HF diets to enhance chemical-induced, but not hormone-induced, mammary carcinogenesis in female rats cannot be explained, but it might be a consequence of the different characteristics of the different models used. For example, in most situations, virgin rats were given a dose of chemical carcinogen at a young age $(35-60 \mathrm{~d})$ when the mammary gland is exquisitely susceptible to tumour induction. In our present model, hormone induction was applied to sexually mature rats and sustained throughout the experimental period by the slow diffusion of hormones from the silastic capsules. Furthermore, as commented by Ip (1993), in previous studies on experimental models of fat intake and mammary cancer, HF intake promotes mammary carcinogenesis only under a very stringent set of conditions, and these might not be duplicated in the setting of fat intake and human breast-cancer risk. Since the reports of the Committee on Diet, Nutrition, and Cancer, National Research Council (1982) and the Committee on Diet and Health, National Research Council (1989), much research on the diet and breast cancers has been done. The hypothesis that dietary fat plays a role in breast cancer has undergone much scientific controversy and debate. Further, in epidemiological studies linking fat intake and breast cancer, there are other factors, such as differences in lifestyle, reproductive history, eating habits, as well as complexity of the total diet which must be considered. This could be the reason why the positive association in international comparisons, the epidemiological evidence of a strong, positive correlation between dietary fat and breast cancer, and the results of most other animal experiments, are not supported by large cohort studies of human breast cancer (Holmes et al. 1999).
Our results from analysis of $\alpha$-tocopherol (vitamin E) in breast tissues showed a similar level in animals in both dietary groups. These results do not support the hypothesis that peroxidation of conjugated double bonds in polyunsaturated fatty acids leads to persistent oxidative stress, causing depletion of antioxidant defence in the target tissue and indirectly contributing to carcinogenesis (Bartsch, 1999). It is interesting to note, however, that $\alpha$-tocopherol levels of hormone-treated rats were consistently higher in both dietary groups than the untreated animals, given that maize oil contains high levels of $\alpha$-tocopherol. This may suggest that the sex hormones have either caused an increase in the antioxidant level in the target organ, or have a role against its depletion from the tissue. With regard to the first possibility, vitamin $\mathrm{E}$ may accumulate in actively dividing tissue, and could possibly be found at higher concentration in proliferating tissue in a malignant or pre-malignant stage (Halliwell \& Gutteridge, 1999). With regard to the second possibility, oestrogens have antioxidant, as well as carcinogenic, properties. It is possible, therefore, that oestrogen can spare or recycle $\alpha$-tocopherol. However, the resulting oxidized form of oestrogen may damage DNA (Liehr, 1997), thereby increasing cancer risk in the face of apparently adequate antioxidant defence. It has also been proposed that dietary fat increases breast-cancer risk by raising blood oestrogen levels (Wu et al. 1999); however, our present results showed that there was no difference in oestrogen levels between the HF- and LF-diet groups, whether treated with hormones or not. This is in agreement with finding of the comparative study of blood concentrations of oestradiol among pre-menopausal Japanese and Caucasian women with different dietary habits (Moore et al. 1991).

Prostate and breast cancers have a great deal in common apart from their high incidence rates and lifetime risks. The organs involved are both under the influences of steroid hormones and related growth factors, and removal of gonads reduces tumour incidences in both sexes (LopezOtin \& Diamandis, 1998). Our present animal model, which uses sex hormones, is considered to be highly relevant for the study of these two homologous cancers in males and females. The current study has shown that an HF diet has no influence on the tumour incidence, latency or type in regard to prostate and mammary cancers induced by sex hormones in Noble rats. Therefore, the long-standing belief that a HF diet promotes the development of these two cancers is not supported by our present results. Furthermore, our results are consistent with the 1997 report from the World Cancer Research Fund (World Cancer Research Fund/American Institute for Cancer Research, 1997) and the Working Group of the UK Committee on Medical Aspects of Food and Nutrition Policy (COMA) 1998, which concluded that the evidence that dietary fat increases cancer risk is not strong. Our findings are also in agreement with two recently published, large-cohort studies (Holmes et al. 1999; Schuurman et al. 1999). In the large ( $n$ 58279) prospective analysis on prostate cancer, Schuurman et al. (1999) concluded that there was no association between prostate carcinoma and intake of energy, total fat, total saturated fatty acids or 
total trans unsaturated fatty acids. In the other study, a prospective cohort dietary study of 88795 women followed up for 14 years, Holmes et al. (1999) concluded that there was no evidence that a lower intake of total fat or of specific types of fat reduces the risk of breast cancer.

In conclusion, this current study, using the Nobel rat model, lends experimental support to the view that dietary fat has no direct influence on either prostate or mammary carcinogenesis. Furthermore, the good agreement seen between the results of this experimental study using the hormone-induced Noble rat model and the results of large human cohort studies of prostate and breast cancer endorses the usefulness of the present animal model in study of human cancers related to sex hormones. This validated model will facilitate the study of dietary influences, molecular mechanisms of aetiology, control and prevention of these common and often fatal cancers.

\section{Acknowledgement}

This work was supported by a RGC grant to Y. C. W. (Project no. HKU7378/00M), and Area of Excellence Scheme (Project no. AoE/P-10/01).

\section{References}

Angwafo FF (1998) Migration and prostate cancer: an international perspective. Journal of the National Medical Association 90, S720-S723.

Aronson WJ, Tymchuk CN, Elashoff RM, McBride WH, McLean C, Wang H \& Heber D (1999) Decreased growth of human prostate LNCaP tumors in SCID mice fed a low-fat, soy protein diet with isoflavones. Nutrition and Cancer 35, 130-136.

Bartsch H (1999) Keynote address: exocyclic adducts as new risk markers for DNA damage in man, pp. 1-16 [B Singer and H Bartsch, editors]. Lyon: IARC Scientific Publications.

Bartsch H, Nair J \& Owen RW (1999) Dietary polyunsaturated fatty acids and cancers of the breast and colorectum: emerging evidence for their role as risk modifiers. Carcinogenesis 20 , 2209-2218.

Blair A \& Fraumeni JF (1978) Geographic patterns of prostate cancer in the United States. Journal of the National Cancer Institute 61, 1379-1384.

Bravo MP, Castellanos E \& del Rey CJ (1991) Dietary factors and prostatic cancer. Urologia Internationalis 46, 163-166.

Breslow N, Chan CW, Dhom G, Drury RA, Franks LM, Gellei B, Lee YS, Lundberg S, Sparke B, Sternby NH \& Tulinius H (1977) Latent carcinoma of prostate of autopsy in seven areas. International Journal of Cancer 20, 680-688.

Carroll KK \& Khor HT (1970) Effects of dietary fat and dose level of 7,12-dimethylbenz(alpha)-anthracene on mammary tumor incidence in rats. Cancer Research 30, 2260-2264.

Carroll KK \& Noble RL (1987) Dietary fat in relation to hormonal induction of mammary and prostatic carcinoma in $\mathrm{Nb}$ rats. Carcinogenesis 8, 851-853.

Chan PC \& Dao TL (1981) Enhancement of mammary carcinogenesis by a high-fat diet in Fischer, Long-Evans, and Sprague-Dawley rats. Cancer Research 41, 164-167.

Chung FL, Chen HJ \& Nath RG (1996) Lipid peroxidation as a potential endogenous source for the formation of exocyclic DNA adducts. Carcinogenesis 17, 2105-2111.

Clarke R (1997) Animal models of breast cancer: experimental design and their use in nutrition and psychosocial research. Breast Cancer Research and Treatment 46, 117-133.
COMA (1988) Nutritional aspects of development of cancer. Report of the Working Group on Diet and Cancer of the Committee on Medical Aspects of Food and Nutrition Policy. Reports on Health and Social Subjects 48, i-xiv.

Committee on Diet, Nutrition, and Cancer, National Research Council (1982) Diet, Nutrition, and Cancer. Washington, DC: National Academy Press.

Committee on Diet and Health, National Research Council (1989) Diet and Health: Implications for Reducing Chronic Disease. Washington, DC: National Academy Press.

Donato KA (1987) Efficiency and utilization of various energy sources for growth. American Journal of Clinical Nutrition 45, 164-167.

Escrich E, Solanas M \& Segura R (1994) Experimental diets for the study of lipid influence on the induced mammary carcinoma in rats: I - Diet definition. In Vivo 8, 1099-1105.

Freedman LS, Clifford C \& Messina M (1990) Analysis of dietary fat, calories, body weight, and the development of mammary tumors in rats and mice: a review. Cancer Research 50, 5710-5719.

Giovannucci E, Rimm EB, Colditz GA, Stampfer MJ, Ascherio A, Chute CC \& Willett WC (1993) A prospective study of dietary fat and risk of prostate cancer. Journal of the National Cancer Institute 85, 1571-1579.

Graham S, Haughey B, Marshall J, Priore R, Byers T, Rzepka T, Mettlin C \& Pontes JE (1983) Diet in the epidemiology of carcinoma of the prostate gland. Journal of the National Cancer Institute 70, 687-692.

Haenszel W \& Kurihara M (1968) Studies of Japanese migrants. I. Mortality from cancer and other diseases among Japanese in the United States. Journal of the National Cancer Institute 40, 43-68.

Halliwell B \& Gutteridge J (1999) Free Radicals in Biology and Medicine. Oxford: Oxford University Press.

Holmes MD, Hunter DJ, Colditz GA, Stampfer MJ, Hankinson SE, Speizer FE, Rosner B, Willett WC, Graham A \& Speizer FEM (1999) Association of dietary intake of fat and fatty acids with risk of breast cancer. Journal of the American Medical Association 281, 914-920.

Hursting SD, Thornquist M \& Henderson MM (1990) Types of dietary fat and the incidence of cancer at five sites. Preventive Medicine 19, 242-253.

Ip C (1993) Controversial issues of dietary fat and experimental mammary carcinogenesis. Preventive Medicine 22, 728-737.

Jemal A, Thomas A, Murray T \& Thun M (2002) Cancer statistics, 2002. CA: A Cancer Journal for Clinicians 52, 23-47.

Kolonel LN, Hankin JH, Lee J, Chu SY, Nomura AM \& Hinds MW (1981) Nutrient intakes in relation to cancer incidence in Hawaii. British Journal of Cancer 44, 332-339.

Kondo Y, Homma Y, Aso Y \& Kakizoe T (1994) Promotional effect of two-generation exposure to a high-fat diet on prostate carcinogenesis in ACI/Seg rats. Cancer Research 54, 6129-6132.

Landis SH, Murray T, Bolden S \& Wingo PA (1999) Cancer statistics, 1999. CA: A Cancer Journal for Clinicians 49, 8-31.

Leung G, Tsao SW \& Wong YC (2002) The effect of flutamide and tamoxifen on sex hormone-induced mammary carcinogenesis and pituitary adenoma. Breast Cancer Research and Treatment 72, 153-162.

Liehr JG (1997) Dual role of oestrogens as hormones and procarcinogens: tumour initiation by metabolic activation of oestrogens. European Journal of Cancer Prevention 6, 3-10.

Lopez-Otin C \& Diamandis EP (1998) Breast and prostate cancer: an analysis of common epidemiological, genetic, and biochemical features. Endocrine Reviews 19, 365-396.

Moore JW, Key TJ, Wang DY, Bulbrook RD, Hayward JL \& Takatani O (1991) Blood concentrations of estradiol and sex hormone-binding globulin in relation to age at menarche in 
premenopausal British and Japanese women. Breast Cancer Research and Treatment 18, Suppl. 1, S47-S50.

Noble RL (1976) A new characteristic transplantable type of breast carcinoma in $\mathrm{Nb}$ rats following combined estrogenandrogen treatment. Proceedings of the American Association of Cancer Research 17, 221.

Noble RL (1977) The development of prostatic adenocarcinoma in $\mathrm{Nb}$ rats following prolonged sex hormone administration. Cancer Research 37, 1929-1933.

Ouyang XS, Wang X, Lee DT, Tsao SW \& Wong YC (2001) Up-regulation of TRPM-2, MMP-7 and ID-1 during sex hormone-induced prostate carcinogenesis in the Noble rat. Carcinogenesis 22, 965-973.

Pandalai PK, Pilat MJ, Yamazaki K, Naik H \& Pienta KJ (1996) The effects of omega-3 and omega- 6 fatty acids on in vitro prostate cancer growth. Anticancer Research 16, 815-820.

Parkin DM, Pisani P \& Ferlay J (1993) Estimates of the worldwide incidence of eighteen major cancers in 1985. International Journal of Cancer 54, 594-606.

Pienta KJ \& Esper PS (1993) Risk factors for prostate cancer. Annals of Internal Medicine 118, 793-803.

Pollard M \& Luckert PH (1986) Promotional effects of testosterone and high fat diet on the development of autochthonous prostate cancer in rats. Cancer Letters 32, 223-227.

Pour PM, Groot K, Kazakoff K, Anderson K \& Schally AV (1991) Effects of high-fat diet on the patterns of prostatic cancer induced in rats by $N$-nitrosobis(2-oxopropyl)amine and testosterone. Cancer Research 51, 4757-4761.

Rose DP, Boyar AP \& Wynder EL (1986) International comparisons of mortality rates for cancer of the breast, ovary, prostate, and colon, and per capita food consumption. Cancer 58, 2363-2371.

Rose DP \& Connolly JM (1991) Effects of fatty acids and eicosanoid synthesis inhibitors on the growth of two human prostate cancer cell lines. Prostate 18, 243-254.

Rose DP, Connolly JM \& Meschter CL (1991) Effect of dietary fat on human breast cancer growth and lung metastasis in nude mice. Journal of the National Cancer Institute 83, $1491-1495$.

Rosen PP (1997) Rosen's Breast Pathology. New York: Lippincott-Raven.

Sakr WA, Haas GP, Cassin BF, Pontes JE \& Crissman JD (1993) The frequency of carcinoma and intraepithelial neoplasia of the prostate in young male patients. Journal of Urology 150, 379-385.

Schuurman AG, van den Brandt PA, Dorant E, Brants HA \& Goldbohm RA (1999) Association of energy and fat intake with prostate carcinoma risk: results from The Netherlands Cohort Study. Cancer 86, 1019-1027.

Sheehy PJ, Morrissey PA \& Flynn A (1994) Consumption of thermally-oxidized sunflower oil by chicks reduces alphatocopherol status and increases susceptibility of tissues to lipid oxidation. British Journal of Nutrition 71, 53-65.

Statland BE (1992) Nutrition and cancer. Clinical Chemistry 38, $1587-1594$.

Takai K (1991) Promotional effects of high fat diet on chemical carcinogenesis of the prostate [in Japanese, with English abstract]. Nippon Hinyokika Gakkai Zasshi - Japanese Journal of Urology 82, 871-880.

Tam NN, Chung SS, Lee DT \& Wong YC (2000) Aberrant expression of hepatocyte growth factor and its receptor, c-Met, during sex hormone-induced prostatic carcinogenesis in the Noble rat. Carcinogenesis 21, 2183-2191.

Tang ZC, Shivapurkar N, Frost A \& Alabaster O (1996) The effect of dietary fat on the promotion of mammary and colon cancer in a dual-organ rat carcinogenesis model. Nutrition and Cancer 25, 151-159.

Vaca CE, Wilhelm J \& Harms-Ringdahl M (1988) Interaction of lipid peroxidation products with DNA. A review. Mutation Research 195, 137-149.

Wang Y, Corr JG, Thaler HT, Tao Y, Fair WR \& Heston WD (1995) Decreased growth of established human prostate LNCaP tumors in nude mice fed a low-fat diet. Journal of the National Cancer Institute 87, 1456-1462.

Wang YZ \& Wong YC (1998) Sex hormone-induced prostatic carcinogenesis in the Noble rat: the role of insulin-like growth factor-I (IGF-I) and vascular endothelial growth factor (VEGF) in the development of prostate cancer. Prostate 35, $165-177$.

West DW, Slattery ML, Robison LM, French TK \& Mahoney AW (1991) Adult dietary intake and prostate cancer risk in Utah: a case-control study with special emphasis on aggressive tumors. Cancer Causes Control 2, 85-94.

Whittemore AS, Kolonel LN, Wu AH, John EM, Gallagher RP, Howe GR, Burch JD, Hankin J, Dreon DM \& West DW (1995) Prostate cancer in relation to diet, physical activity, and body size in blacks, whites, and Asians in the United States and Canada. Journal of the National Cancer Institute 87, 652-661.

Wong YC \& Wang YZ (2000) Growth factors and epithelialstromal interactions in prostate cancer development. International Review of Cytology 199, 65-116.

Wong YC, Wang YZ \& Tam NN (1998) The prostate gland and prostate carcinogenesis. Italian Journal of Anatomy and Embryology 103, 237-252.

Wong YC, Xie W \& Tsao SW (2000) Structural changes and alteration in expression of TGF-beta1 and its receptors in prostatic intraepithelial neoplasia (PIN) in the ventral prostate of noble rats. Prostate 45, 289-298.

World Cancer Research Fund/American Institute for Cancer Research (1997) Food, Nutrition and The Prevention of Cancer: A Global Perspective. Philadelphia, PA: American Institute for Cancer Research.

Wu AH, Pike MC \& Stram DO (1999) Meta-analysis: dietary fat intake, serum estrogen levels, and the risk of breast cancer. Journal of the National Cancer Institute 91, 529-534.

Xie B, Tam NN, Tsao SW \& Wong YC (1999a) Co-expression of vascular endothelial growth factor (VEGF) and its receptors (flk-1 and flt-1) in hormone-induced mammary cancer in the Noble rat. British Journal of Cancer 81, 1335-1343.

Xie B, Tsao SW \& Wong YC (1999b) Induction of high incidence of mammary tumour in female Noble rats with a combination of 17beta-oestradiol and testosterone. Carcinogenesis 20, 1069-1078.

Xie B, Tsao SW \& Wong YC (1999c) Sex hormone-induced mammary carcinogenesis in female Noble rats: expression of TGF-beta1 and its receptors, TGF-alpha, and EGF-R in mammary carcinogenesis. Breast Cancer Research and Treatment 58, 227-239.

Xie B, Tsao SW \& Wong YC (1999d) Sex hormone-induced mammary carcinogenesis in female noble rats: the role of androgens. Carcinogenesis 20, 1597-1606.

Xie B, Tsao SW \& Wong YC (2000a) Sex hormone-induced mammary carcinogenesis in the female Noble rats: expression of bcl-2 and bax in hormonal mammary carcinogenesis. Breast Cancer Research and Treatment 61, 45-57.

Xie W, Wong YC \& Tsao SW (2000b) Correlation of increased apoptosis and proliferation with development of prostatic intraepithelial neoplasia (PIN) in ventral prostate of the Noble rat. Prostate 44, 31-39.

Xie W, Wong YC, Tsao SW \& Wong NS (2000c) Expression of a kallikrein-like protein in prostatic intraepithelial neoplasia in ventral prostate of the noble rat. Prostate 42, 8-17.

Zock PL (2001) Dietary fats and cancer. Current Opinion in Lipidology 12, 5-10. 